\title{
The Royal College of Paediatrics and Child Health programme for subspecialty training
}

\author{
M McGraw, G Ng
}

Arch Dis Child 2006;91:71-73. doi: 10.1136/adc.2004.066688

The National Grid is a training scheme that represents a unique partnership between Deaneries and the Royal College of Paediatrics and Child Health (RCPCH) in offering through national competition, equitable access to high quality subspecialty training. Paediatrics is unusual in that within the umbrella Certificate of Completion of Specialist Training in paediatrics there is the potential to train in one of 13 recognised paediatric subspecialties.

See end of article for authors' affiliations

.....................

Correspondence to: Dr M McGraw, Department of Paediatric Nephrology, Bristol Royal Hospital for Children, Upper Maudlin Street, Bristol BS2 8BJ, UK; mary. mcgraw@ubht.swest.nhs. uk

Accepted

10 February 2005
$\mathrm{P}$ rior to the introduction of the specialist registrar training scheme, entry to subspecialty training programmes was through national competition into senior registrar posts from general registrar posts. With the introduction of the scheme, general and subspecialty posts were incorporated into a unified training programme. The number of training posts is limited and each deanery cannot offer a full range of subspecialty training opportunities. This introduced an inequity where only of those trainees fortunate enough to be appointed to a deanery in which subspecialty of their choice was available were able to be offered the opportunity to train in that subspecialty. The introduction of the RCPCH programme for subspecialty training (known as the National Grid) has restored the previously available opportunity for all to be able to apply for subspecialty training of their choice. Through the scrutiny of the training programmes by the College Specialist Advisory Committees (CSACs), training programmes are guaranteed to meet the necessary standards required to delivery specialty training. Moreover, the training scheme also has an important role in workforce planning as the number of appointments made is determined by the anticipated consultant requirement.

\section{HOW DOES IT WORK?}

Programmes of subspecialist training are submitted from throughout the UK. Specialty Advisory Committees confirm that these programmes have subspecialty training approval. They also advise on the appropriate number of appointments to be made. This number is based on the anticipated need for consultants in the subspecialty at the time, and is revised on an annual basis as this need changes. Applicants are specialist registrars in year 3 or additionally from 2004, in year 2. They rank their preferences for programmes but the interview panel does not know these preferences. Candidates are shortlisted against the short-listing criteria in the person specification. An independent selection panel, chaired by a Regional Advisor who will not be a subspecialist in that specialty, interviews candidates, regardless of their current location around the country or the location of the programme(s) that they wish to enter. The panel does not necessarily contain individuals from the training centres offered but consists of members of the CSAC who act on behalf of their colleagues.

Those interviewed are first judged as to whether they are suitable for subspecialist training. Applicants judged not to meet the full criteria in the person specification are not considered for placement. Those meeting the criteria are ranked according to merit and allocated programmes according to their preferences with the highest ranking getting their first choice; the second rank, the first of the remaining available; and so on. The allocation of programmes, based on the ranking and the applicants' preferred programmes as indicated on the preference sheet, is undertaken by the Northern Deanery, which acts on behalf of all the other deaneries. The selection panels do not take part in this stage of the process. If there are more applicants than available places, it is possible for more candidates to be judged suitable for training in the subspecialty than there are programmes available.

\section{OUTCOMES OF THE TRAINING SCHEME}

The National Grid is now about to enter its fourth year. The number of the programmes offered has increased each year as further subspecialties have been offered. In 2002 the scheme was piloted with only four subspecialties, increasing to nine subspecialties in 2003 and 13 subspecialties in 2004. The number of applicants has increased as a result of this, and the adaptation of the entry criteria extending the offer of opportunities to trainees earlier in their training.

Seventy two per cent of applicants were shortlisted in 2004 compared to $85 \%$ in 2003 . In 2004, $83 \%$ of those interviewed were thought to be appointable, and $58 \%$ of those interviewed were appointed; $57 \%$ of applicants interviewed were appointed in 2003. For both years $76 \%$ of posts were filled and $58 \%$ of trainees have been offered their first programme choice.

The unfilled posts were returned to their deaneries to be offered to local trainees wishing to gain subspecialty experience as part of a general programme. Posts remained unfilled despite applicants being considered appointable because those applicants chose not to apply for, or accept, the remaining programmes. 


\section{Glossary}

- Higher specialist training (Calman training scheme): minimum entry requirements are 24 months general professional training (SHO grade) and MRCPCH examination (or equivalent). Trainees enter by competitive interview and are awarded a National Training Number (NTN) which identifies them as a higher specialist trainee (specialist registrar). Training consists of 60 months (minimum 48 months) in the specialist registrar grade

- Certificate of Completion of Specialist Training (CCST)*: if the programme is completed successfully the candidate will be awarded a CCST which enables them to be registered as a paediatric specialist and apply for consultant posts

- College Specialty Advisory Committee (CSAC): the $\mathrm{RCPCH}$ advises on standards for training and each subspecialty has an advisory committee that advises on training in the subspecialty

- Postgraduate Deanery: an organisation that is responsible for the delivery of postgraduate training in all specialties in a defined geographical locality

- Regional Advisor: an elected RCPCH representative who works with their own local deanery to ensure training delivered meets RCPCH standards

*Known as the Certificate of Completion of Training (CCT) from 30 September 2005.

Some specialties, for example metabolic medicine and rheumatology, are very small; training is limited to two or three centres and the number of applicants is correspondingly small. Other specialties, for example neonatal medicine, are much larger. Although all deaneries can offer at least one training programme in neonatal medicine, balancing availability according to an individual trainee's wish to train as a neonatologist is difficult at a local level. Through the national scheme it is possible to offer more trainees the opportunity of entering an approved programme. A summary of the details of the past two years is presented in table 1.

As training opportunities for subspecialty training are limited, trainees need to be prepared to relocate deanery for the entire programme, or to receive specific modules of training. In 2003, 50\% of trainees needed to relocate, and in $2004,60 \%$ of trainees needed to relocate. Of these, $61 \%$ needed to relocate because the training opportunity in their chosen subspecialty was not available in their own deanery. Relocation can provide difficulties for young doctors with working partners and families. However, the number of children requiring the expertise of a tertiary centre is fortunately few, therefore that expertise, and thus training, is necessarily limited to a small number of centres.

At the outset of the scheme there was concern that the net direction of movement of trainees may be towards London which is able to offer more tertiary training opportunities. However, experience has shown that the overall net loss or gain per deanery is small (see table 2).

\section{ACCEPTABILITY OF THE TRAINING SCHEME}

Acceptability can be viewed as the confidence that the users have in the scheme. A survey has been conducted of trainees who have participated in the scheme over the past three years, ${ }^{1}$ with the aim of using the feedback to improve the process in the future. The support for the Grid was high and most trainees felt that the National Grid did offer a structured programme of training. There were many positive comments about programmes being well taught. Inevitably there were comments about the tension between training and service provision. Trainees supported the equity of access to training, and the ability to have their "training needs formally recognised", " to give them a sense of belonging", "to give supervisors a clear idea of how to prepare them for their future responsibilities", and "to mark you out as a subspecialty trainee within the region".

The majority of criticisms both from the trainees survey, and a survey conducted by the neonatal Specialty Advisory Committee, ${ }^{2}$ surrounded the process of application and interview. The posts are advertised nationally in the British Medical Journal in the first two weeks of January every year and a Grid guide detailing the processes involved is on the Royal College of Paediatrics and Child Health website. ${ }^{3}$ Information is given to Regional Advisors, Specialty Advisory Committees, and to the regional trainees to cascade in their own areas. Despite this a third of trainees surveyed did not feel well informed of the process.

There were also concerns regarding poor communication following the interviews. Candidates cannot be informed on the day of interview if they are to be offered a programme as the matching of successful applicants to programmes is done by the lead deanery after the interviews. It is common in other medical interviews to be told at the interview, or the

Table 1 Applicants to the National Grid, 2003 and 2004

\begin{tabular}{|c|c|c|c|c|c|c|c|c|}
\hline & \multicolumn{2}{|c|}{ No. of posts } & \multicolumn{2}{|c|}{ No. of applicants } & \multicolumn{2}{|c|}{ No. short-listed } & \multicolumn{2}{|c|}{ No. of candidates appointed } \\
\hline & 2004 & 2003 & 2004 & 2003 & 2004 & 2003 & 2004 & 2003 \\
\hline Clinical Pharmacology & 1 & $\mathrm{n} / \mathrm{a}$ & 1 & $\mathrm{n} / \mathrm{a}$ & 1 & $\mathrm{n} / \mathrm{a}$ & 1 & $n / a$ \\
\hline Community Paediatrics & 12 & $\mathrm{n} / \mathrm{a}$ & 4 & $n / a$ & 3 & $\mathrm{n} / \mathrm{a}$ & 3 & $n / a$ \\
\hline Endocrinology & 3 & 8 & 9 & 9 & 7 & 8 & 3 & 4 \\
\hline Gastroenterology & 3 & 8 & 9 & 13 & 7 & 11 & 4 & 7 \\
\hline Immunology & 3 & 2 & 13 & 6 & 7 & 6 & 3 & 2 \\
\hline Intensive Care & 5 & $\mathrm{n} / \mathrm{a}$ & 6 & $\mathrm{n} / \mathrm{a}$ & 5 & $\mathrm{n} / \mathrm{a}$ & 3 & $\mathrm{n} / \mathrm{a}$ \\
\hline Metabolic & 2 & $\mathrm{n} / \mathrm{a}$ & 3 & $n / a$ & 3 & $\mathrm{n} / \mathrm{a}$ & 2 & $n / a$ \\
\hline Neonatology & 19 & 17 & 43 & 19 & 29 & 18 & 19 & 14 \\
\hline Nephrology & 4 & 5 & 7 & 7 & 7 & 5 & 4 & 3 \\
\hline Neurology & 6 & 8 & 21 & 23 & 13 & 21 & 6 & 8 \\
\hline Oncology & 11 & 7 & 17 & 13 & 17 & 11 & 10 & 6 \\
\hline Respiratory & 9 & 11 & 9 & 9 & 4 & 9 & 2 & 4 \\
\hline Rheumatology & 1 & 4 & 0 & 9 & 0 & 4 & 0 & 4 \\
\hline Total & 79 & 70 & 142 & 108 & 103 & 93 & 60 & 52 \\
\hline
\end{tabular}




\begin{tabular}{|c|c|c|c|c|c|c|}
\hline \multirow[b]{2}{*}{ Deanery } & \multicolumn{2}{|c|}{$\begin{array}{l}\text { Trainees remaining } \\
\text { within region }\end{array}$} & \multicolumn{2}{|l|}{ Losses } & \multicolumn{2}{|l|}{ Gains } \\
\hline & 2004 & 2003 & 2004 & 2003 & 2004 & 2003 \\
\hline London & 9 & 14 & 5 & 5 & $10^{*}$ & 3 \\
\hline Kent, Sussex, and Surrey† & 0 & & 5 & & 0 & \\
\hline West Midlands & 2 & 2 & 0 & 0 & 0 & 2 \\
\hline Mersey & 2 & 1 & 4 & 2 & 2 & 1 \\
\hline Wales & 2 & 1 & 0 & 3 & 1 & 1 \\
\hline Oxford & 0 & 0 & 1 & 1 & 2 & 2 \\
\hline Yorkshire & 5 & 2 & 1 & 1 & 2 & 1 \\
\hline Trent & 1 & 0 & 1 & 1 & 2 & 0 \\
\hline Mid Trent & 1 & 0 & 2 & 2 & 2 & 2 \\
\hline South Trent & 0 & 0 & 0 & 0 & 1 & 2 \\
\hline West Scotland & 0 & 0 & 1 & 0 & 2 & 1 \\
\hline North West & 1 & 2 & 2 & 3 & 1 & 3 \\
\hline East Anglia & 0 & 2 & 3 & 3 & 1 & 0 \\
\hline South West & 1 & $\overline{1}$ & 2 & 2 & 3 & 4 \\
\hline Northern & 1 & 0 & 3 & 1 & 1 & 2 \\
\hline Wessex & 1 & 2 & 0 & 1 & 4 & 1 \\
\hline SE Scotland & 0 & 0 & 2 & 0 & 0 & 0 \\
\hline $\mathrm{N}$ Ireland & 0 & 0 & 1 & 0 & 0 & 0 \\
\hline Total & 26 & 27 & 33 & 25 & $34^{*}$ & 25 \\
\hline
\end{tabular}

next day, and therefore the delay in this process is unfamiliar. However, procedures have been put in place for future years to improve this aspect of communication.

Trainees indicated that they had chosen specific programmes because of the location rather than the content of the training programme. This is perhaps not surprising given that all programmes are accredited to provide training for the tertiary curriculum and thus the discriminating feature is the location. It could however be perceived as being disappointing that trainees deemed appointable do not take up available posts because they do not wish to move to the location in which a programme is available.

Relocation is a major issue for the trainees. Although a few were positive ("actually good to change region"), the majority were negative ("a massive disruption to my whole family"; "very stressful...especially after being settled in the region for seven years"; "we have lives, families, and financial commitments that stop us moving around the country"). The RCPCH does have sympathy for doctors with families for whom movement around the country is difficult. However, relocation is essential for many to be able to obtain subspecialty training which would not be available in their own deanery, and as one trainee commented: "It depends how committed you are to your chosen specialty over your personal life".

\section{CONCLUSION}

The National Grid remains a unique scheme in the UK and its administration continues to improve with experience. The recent workforce survey ${ }^{4}$ shows that $37 \%$ of consultants are working as specialists in tertiary centres. Given the limited opportunities to gain entry to training, it is important that there is a national scheme providing an approved route to subspecialist accreditation which is matched to workforce needs, and which provides equity of access to quality assured training.

\section{ACKNOWLEDGEMENTS}

The authors would like to thank Dr Patricia Hamilton, Vice President for Training and Assessment, and Robert Heller, RCPCH Grid Administrator for all their help with the manuscript. We would also like to thank Professor Peter Hill, Lead Dean for Paediatrics for all his support with the administration of the subspecialty training scheme.

\section{Authors' affiliations}

M McGraw, Department of Paediatric Nephrology, Bristol Royal Hospital for Children, Bristol, UK

G Ng, Department of Neonatology, St George's Hospital, London, UK

Competing interests: none

\section{REFERENCES}

$1 \mathrm{Ng}$ GYT, Heller R, Hamilton PA. Evaluation of trainees' views on the Paediatric National Grid process, http://www.rcpch.ac.uk/trainees.

2 RCPCH. Subspecialty training in neonatal medicine. The National Grid: the first two years, Royal College of Paediatrics and Child Health Specialty Advisory Committee, 2003.

3 National Grid Training Scheme. December 2003, revised 2004.

4 RCPCH Workforce Census. September 2003. 